\title{
Kemas Ulang Informasi Koleksi Perpustakaan sebagai Upaya Pemenuhan Kebutuhan Informasi para Pemustaka
}

\author{
Jody Santoso ${ }^{1}$ \\ ${ }^{1}$ UPT Perpustakaan Institut Seni Indonesia Yogyakarta \\ Jalan Parangtritis km. 6,5 Yogyakarta \\ HP.: 085227009819; Email: jodysantoso16@gmail.com
}

\begin{abstract}
Abstrak
Koleksi perpustakaan terus mengalami perkembangan dengan pesat seiring dengan perkembangan teknologi informasi yang dapat menyebabkan banjir informasi. Hal itu berdampak pada pemakai informasi yang merasa terkendala dalam memilih dan mendapatkan informasi yang relevan dengan apa yang dibutuhkannya. Daya tarik kemas ulang informasi koleksi perpustakaan dapat menjadi salah satu solusi untuk menjawab kegelisahan para pemakai informasi. Dengan kemas ulang informasi koleksi perpustakaan yang dapat menghasilkan kemasan informasi yang lebih menarik, relevan, dan cepat dalam temu kembali informasi, menjadikan pemustaka dapat dengan cepat, tepat, dan mudah menemukan informasi yang dibutuhkan sehingga merasa puas terhadap layanan perpustakaan dalam memenuhi kebutuhan informasi mereka. Pemustaka akan diuntungkan dengan adanya kemas ulang informasi koleksi perpustakaan karena akan menghemat biaya dan waktu dari pemustaka dalam proses pencarian, pemilihan dan pemerolehan informasi yang dibutuhkan.
\end{abstract}

Kata kunci: kemas ulang informasi; koleksi perpustakaan; daya tarik

\begin{abstract}
Re-Pack Library Collection Information as an Effort to Meet the Information Needs of The Library. Library collections continue to develop rapidly, and information technology development that can cause a flood of information. It impacts information users who feel constrained in choosing and getting information that is relevant to what they need. The appeal of repacking library collection information can be one solution to answer the anxiety of information users. By repacking library collection information that can produce more engaging, relevant, and fast packaging of information in re-meeting information, making the library can quickly, precisely, and easily find the required information so that they are satisfied with library services in meeting their information needs. The library will benefit from the re-mission of library collection information because it will save the cost and time of the library in the process of searching, selecting and obtaining the required information.
\end{abstract}

Keywords: re-pack information; library collections; attractions

\section{A. Pendahuluan}

Koleksi perpustakaan mempunyai berbagai bentuk bahan yakni ada yang berbentuk tercetak dan ada yang berbentuk elektronik. Pemikiran dan gagasan yang dimiliki seseorang banyak diwujudkan dan dituliskan dalam bentuk buku, jurnal, repository dan sebagainya yang diterbitkan dalam media cetak maupun elektonik/online dan dikoleksi di perpustakaan. Koleksi perpustakaan merupakan unsur utama yang dalam kegiatan pelayanan di perpustakaan. Dengan koleksi yang lengkap dan dapat memenuhi kebutuhan pemustakanya maka akan menjadi salah satu penentu kepuasan pemustaka terhadap layanan perpustakaan. 
Pemustaka mempunyai latar belakang pendidikan yang beragam baik bidang dan tingkatannya terutama pada perpustakaan umum. Pendidikan para pemustaka ini akan berpengaruh terhadap kebutuhan informasinya dan media atau bentuk informasi yang disajikan. Meskipun berasal dari latar belakang pendidikan yang berbeda, tetapi mereka mempunyai satu kesamaan tujuan ketika berkunjung di perpustakaan, yaitu ingin memenuhi kebutuhan informasi mereka. Masyarakat yang ingin memenuhi kebutuhan informasi di perpustakaan tersebut dapat disebut sebagai pemakai informasi.

Dalam usaha memenuhi kebutuhan akan informasi, maka para pemakai informasi dapat memanfaatkan kemajuan teknologi informasi berbasis online (internet) sehingga informasi yang dibutuhkan akan mudah didapatkan, cepat dalam temu kembali, dan jumlah informasi yang diperoleh akan banyak. Dengan kemudahan mendapatkan informasi ini maka dapat menyebabkan terjadinya banjir informasi. Ketika informasi ini dapat dengan mudah diperoleh dan jumahnya sangat banyak maka akan membuat masyarakat kadang bingung dengan informasi yang diperoleh karena informasi tersebut kadang perlu dianalisis kebenaranya secara mendalam dan lengkap. Ketika informasi yang diperoleh hanya sebagian dan tidak utuh atau tidak disertai data dukung atau sumber yang terpercaya maka hal ini akan menjadi sampah informasi. Para pemakai informasi sebelum menggunakan informasi yang diperoleh maka perlu melakukan analisis kebenaran dan mencari sumber informasi terpercaya yang salah satunya adalah perpustakaan. Informasi yang diperoleh dari sumber yang terpercaya maka informasi tersebut memberikan nilai tambah pengetahauan baru bagi pemakai informasinya.

Saat ini banyak perpustakaan terutama perpustakaan perguruan tinggi yang memanfaatkan teknologi informasi ini dalam memberikan layanan perpustakaan. Koleksi digital merupakan koleksi yang paling mudah di layankan karena dapat di akses secara online dan dapat diakses dimanapun dan kapanpun. Koleksi digital ini dapat diperoleh oleh perpustakaan dengan membeli atau berlangganan seperti ebook dan ejournal, dan dapat juga diperoleh dengan melakukan kemas ulang informasi yang dimiliki perpustakaan. Proses kemas ulang informasi ini dapat dilakukan dengan cara alih media seperti koleksi dalam bentuk tercetak menjadi koleksi digital.

Dengan kemas ulang informasi maka koleksi perpustakaan akan lebih mudah dan cepat untuk diakses sehingga pada akhirnya akan dapat memenuhi kebutuhan informasi para pemakai informasi. Kemas ulang informasi ini juga dapat menjadi daya tarik dalam pemanfaatan layanan koleksi perpustakaan bagi para pemakai informasi. Dalam makalah ini akan dibahas mengenai manfaat kemas ulang informasi koleksi perpustakaan bagi pemustaka dalam usaha memenuhi kebutuhan informasinya.

\section{B. Hasil dan Pembahasan}

Perkembangan informasi sangat pesat seiring dengan perkembangan teknologi informasi, yang mana menyebabkan terjadinya banjir informasi. Pemakai informasi dihadapkan kepada beberapa pemasalahan yang disebabkan oleh perkembangan teknologi informasi, diantaranya yaitu banjir infomasi, tidak sesuainya informasi yang disajikan, kurang tepatnya kandungan informasi yang diberikan, kurang relevannya informasi yang tersedia, selain itu juga adanya informasi yang belum tentu kebenarannya.

Salah satu upaya yang dilakukan oleh perpustakaan untuk mengatasi hal tersebut di atas adalah dengan melakukan kemas ulang informasi koleksi perpustakaan. Definisi informasi (information) dari (Reitz, 2014) yaitu data yang disajikan dalam bentuk yang mudah dipahami, yang maknanya telah dikaitkan dalam konteks penggunaannya. Dalam pengertian yang lebih dinamis, informasi merupakan pesan yang disampaikan dengan menggunakan media komunikasi atau ekspresi dan apakah pesan yang disampaikan itu merupakan pesan yang informatif atau tidak, hal itu tergantung pada persepsi pribadi dari penerima pesan. Kemudian arti dari kemas ulang (repackaging) menurut (Reitz, 2014) adalah menerbitkan kembali buku yang telah diterbitkan sebelumnya dengan menggunakan format yang 
berbeda, hal tersebut mempunyai maksud untuk meningkatkan daya tarik bagi pembacanya, hal yang dilakukan diantaranya dengan membuat harga yang terjangkau seperti melakukan penerbitan edisi paperback, atau dengan membuat penerbitan yang lebih mudah dibaca, seperti menerbitkan dalam edisi cetak besar.

Menurut Pudjiastuti (n.d: 1) definisi kemas ulang informasi adalah mengemas informasi kembali, atau mengubah dari satu bentuk informasi ke bentuk lainnya. Kemas ulang informasi bisa berupa perubahan bahasa satu ke bahasa lain, misalnya terjemahan, intepretasi, dan bisa pula berupa perubahan fungsi seperti revisi, ringkasan, analisis, risalah, bahkan anotasi. Sedangkan Fatmawati (2009: 29) mendefinisikan kemas ulang informasi merupakan kegiatan penataan ulang yang dimulai dari menyeleksi berbagai informasi dari sumber yang berbeda, mendata informasi yang relevan, menganalisis, mensintesa, dan menyajikan informasi yang sesuai dengan kebutuhan pengguna. Jusni, Djatin dan Hartinah, berpendapat bahwa pengemasan informasi adalah kegiatan yang dimulai dari menyeleksi berbagai informasi dari sumber yang berbeda, mendata informasi yang relevan, menganalisis, mensintesa, dan menyajikan informasi yang sesuai dengan kebutuhan pemakai. Informasi yang dikemas kembali memberi kemudahan dalam penyebaran informasi dan temu kembali informasi. Menurut Widyawan (2013) kemas ulang informasi merupakan salah satu cara untuk meningkatkan pelayanan perpustakaan, terutama dalam era informasi elektronik. Pelayanan kemas ulang informasi memerlukan proses sistematik untuk memberikan nilai tambah pelayanan perpustakaan. Dalam penambahan nilai termasuk analisis, sintesis, penyuntingan, penerjemahan dan transmisi simbolik serta format media atau pembawa pesan. Jika pustakawan tidak menjamin, kekinian, keakuratan, ketepatan, kelengkapan produk kemas ulang dapat menyebabkan kurang berartinya pelayanan kemas ulang informasi kepada pemustaka.

Dengan mengacu beberapa pendapat di atas, yang dimaksud kemas ulang informasi koleksi perpustakaan yaitu mengemas kembali informasi yang ada di dalam koleksi perpustakaan menjadi kemasan atau bentuk yang lebih menarik, mudah dipahami, dan jelas kebenaran sumber informasi tersebut sehingga dapat meningkatkan daya tarik bagi pembacanya. Dimulai dari menyeleksi berbagai informasi dari sumber yang berbeda dan jelas kebenarannya, melakukan pendataan informasi yang relevan, menganalisis dan mensintesa informasi yang terkumpul, kemudian menyajikan informasi yang sesuai dengan kebutuhan pemustaka. Selain itu juga kemas ulang informasi dapat memberikan kemudahan dalam diseminasi informasi dan kegiatan proses temu kembali informasi.

Di dalam kegiatan pengemasan informasi perlu menerapkan prinsip-prinsip pengemasan informasi agar kemasan informasi yang dihasilkan dapat menarik dan sesuai dengan kebutuhan pemustaka. Adapun prinsip-prinsip pengemasan informasi menurut Pebrianti (2015: 29) yaitu:

1. Benar dan logis, berarti dapat dipercaya dan dapat diterima oleh akal sehat.

2. Sistematis, yaitu bahwa informasi disajikan secara runut, bertahap dan berkesinambungan sesuai dengan alur pikir.

3. Aplikatif, yaitu bahwa informasi yang dikemas ulang dapat diterapkan oleh pemakai informasi.

4. Tuntas dan menyeluruh, adalah informasi berasal dari berbagai sumber yang kompeten dan telah melalui proses penelaahan, sehingga dapat menjamin kebaruan dan kelengkapan informasi yang disajikan.

5. Jelas, yang artinya mudah dipahami pengguna serta tidak menimbulkan salah tafsir. Oleh karena itu, pengemasan informasi perlu memperhatikan tingkat kecerdasan pengguna, menggunakan istilah atau kata-kata yang sederhana sehingga dapat dipahami oleh penggunanya, dengan gaya bahasa yang tidak formal.

6. Ringkas, yaitu langsung ke permasalahan yang dibahas, tidak panjang lebar agar ide pokok tidak kabur.

7. Terbuka yang mempunyai arti bahwa informasi yang disajikan memungkinkan untuk diperbarui apabila ada perkembangan baru.

8. Bermanfaat bagi sasaran yang dituju, yaitu bahwa informasi tersebut dapat bermanfaat bagi pemakai informasi.

Di dalam proses kemas ulang informasi ada langkah-langkah yang harus dilaksanakan agar 
kegiatan tersebut dapat berjalan sesuai dengan apa yang diharapkan yaitu dapat membuat kemas ulang informasi menarik minat pemustaka dan sesuai dengan kebutuhan informasi pemustaka. Jusni, Djatin dan Hartinah, (n.d.: 2) mengemukakan langkah-langkah dalam proses kemas ulang informasi yaitu: (1) Menyeleksi dan menetapkan topik dari kemasan yang akan dibuat dan informasi yang akan dicakup; (2) Menentukan strategi dalam mencari informasi; (3) Menentukan lokasi informasi dan cara mengaksesnya; (4) Menggunakan informasi dengan cara mengevaluasi dan mensitir informasi; (5) Mensintesa yaitu mengemas informasi; (6) Mengevaluasi produk yang dibuat, dan mengevaluasi proses pembuatannya. Untuk membuat suatu kemasan informasi yang baik, harus didukung oleh informasi penting yang cukup atau memadai.

Tujuan diadakannya kemas ulang informasi koleksi perpustakaan yaitu melayankan informasi perpustakaan dengan bentuk kemasan yang lebih menarik dan mudah dalam temu kembali informasi, sehingga pemustaka tertarik menggunakannya dalam usaha untuk memenuhi kebutuhan informasinya. Dengan kemas ulang informasi, pemustaka dapat menghilangkan rasa was-was yang ditimbulkan karena adanya banjir informasi sebagai akibat dari perkembangan teknologi informasi.

Sedangkan pengertian dari koleksi perpustakaan dijabarkan sebagai berikut. Koleksi perpustakaan merupakan salah satu komponen di suatu perpustakaan. Kualitas koleksi suatu perpustakaan yang baik dan memadai dapat memberikan pelayanan yang baik kepada pemustaka. Menurut Yulia (2014: 1.5) yang dimaksud dengan koleksi perpustakaan adalah semua bahan pustaka yang dikumpulkan, diolah, dan disimpan untuk disebarluaskan kepada masyarakat guna memenuhi kebutuhan informasi mereka.

Menurut Reitz (2014) pengertian koleksi perpustakaan adalah akumulasi total buku dan bahan lain yang dimiliki oleh suatu perpustakaan, dikatalogkan dan diatur untuk kemudahan akses, seringkali terdiri dari beberapa koleksi yang lebih kecil (referensi, buku yang beredar, serial, dokumen pemerintah, buku langka, koleksi khusus, dll.).
Sulistyo-Basuki (2009: 8) memberi pengertian tentang koleksi perpustakaan adalah bahan pustaka yang mencakup: (a) Karya cetak atau karya grafis seperti buku, majalah, surat kabar, disertasi, dan laporan; (b) Karya non cetak atau karya non rekam seperti piringan hitam, rekaman audio, kaset dan video; (c) Bentuk mikro seperti mikro film, mikrofis, dan microopaque; serta (d) Karya dalam bentuk elektronik seperti disket, pita magnetik, dan kelongsong elektronik (catridge) yang diasosiasikan dengan komputer.

Undang-undang Nomor 43 Tahun 2007 tentang Perpustakaan, mendefinisikan tentang koleksi perpustakaan yaitu semua informasi dalam bentuk karya tulis, karya cetak, dan/atau karya rekam dalam berbagai media yang mempunyai nilai pendidikan, yang dihimpun, diolah, dan dilayankan. (Indonesia, 2007: 2). Dalam kaitannya dengan koleksi perpustakaan masih dalam undangundang yang sama pasal 12 disebutkan bahwa koleksi perpustakaan diseleksi, diolah, disimpan, dilayankan, dan dikembangkan sesuai dengan kepentingan pemustaka dengan memperhatikan perkembangan teknologi informasi dan komunikasi (Indonesia, 2007: 9).

Dari beberapa pengertian di atas dapat disimpulkan bahwa koleksi perpustakaan adalah semua bahan pustaka dalam bentuk karya tulis, karya cetak, dan karya rekam yang dikumpulkan, diseleksi, diolah, disimpan dan digunakan dalam pelayanan kepada pencari informasi untuk memenuhi kebutuhan informasi mereka dalam suatu perpustakaan. Di perpustakaan perguruan tinggi kemas ulang informasi ini dapat dilakukan dengan mengalih mediakan koleksi tugas akhir, laporan penelitian, buku karya dosen dan sebagainya baik para dosen maupun mahasiswa sehingga akan dapat terwujud repository koleksi institusi yang lengkap dan relevan dengan kebutuhan pemustakanya.

Bagi pemustaka yang koleksinya dapat di akses secara online karena telah dalam bentuk koleksi digital maka para pemustaka tidak perlu datang ke perpustakaan. Akan tetapi di dalam perpustakaan yang koleksi perpustakaannya yang masih dalam bentuk tercetak maka pemustaka atau pencari informasi akan datang ke perpustakaan untuk 
memanfaatkan koleksi dengan cara membaca, mencatat, memfotokopi dan meminjam dan cara paling dominan dalam memanfaatkan koleksi perpustakaan adalah dengan membaca ditempat. Dan sesuai urutan terbanyak adalah meminjam, mencatat atau menyalin dan melakukan fotokopi. Selain itu untuk mendapatkan informasi dalam menyelesaikan tugas kuliah, ada juga yang memanfaatkan koleksi sebagai penyaluran hobi membaca (Wahyuntini dan Endarti, 2021: 4). Ketika pemustaka yang ada di perpustakaan perguruan tinggi dan banyak memanfaatkan koleksi disana maka ada perubahan dalam hal prestasi akademik para mahasiswa. Prestasi akademik mahasiswa yang datang ke perpustakaan untuk memanfaatkan layanan perpustakaan cenderung tinggi (Bandono dan Susilowati, 2021: 23).

Koleksi bahan pustaka yang dimiliki oleh perpustakaan agar memberikan manfaat dan terus digunakan oleh para pemustaka maka dalam pengelolaannya harus diselaraskan dengan visi dan misi lembaga induk yang menaungi perpustakaan tersebut terutama perpustakaan perguruan tinggi, selain itu tetap mengutamakan kualitas layanan dan ketersediaan koleksi yang dimilikinya. Agar dapat menunjang tujuan dan program dari lembaga induknya maka koleksi perpustakaan harus lengkap dengan artian bahwa koleksi perpustakaan beragam subjeknya dan memadai jumlahnya. Selain itu koleksi perpustakaan diolah dan disajikan sesuai sistem tertentu agar mudah dalam temu kembali informasi. Pemanfaatan penggunaan teknologi informasi secara maksimal dan selalu mengikuti perkembangannya akan sangat mendukung layanan perpustakaan, koleksi perpustakaan yang lengkap serta mempunyai variasi bentuk koleksi yang salah satunya dalam bentuk digital (melalui pembelian, langganan dan kemas ulang informasi) akan semakin memudahkan pemustaka dan memberikan kepuasan terhadap layanan perpustakaan.

\section{Kesimpulan dan Saran}

Koleksi perpustakaan merupakan komponen utama di perpustakaan dalam kegiatan pelayanan kepada pemustaka. Koleksi perpustakaan terus berkembang seiring dengan perkembangan teknologi informasi yang dapat menyebabkan banjir informasi.

Pemenuhan ketersediaan koleksi dalam mendukung layanan perpustakaan yang cepat, tepat, dan mudah adalah penyediaan koleksi dengan kemas ulang informasi koleksi perpustakaan. Dengan kemas ulang informasi koleksi perpustakaan yang menarik dan relevan serta mudah dalam temu kembali informasi, dapat menjawab tentang pemenuhan kebutuhan informasi pemustaka yang dibayangi akan adanya banjir informasi. Selain itu juga dapat menjadi daya tarik tersendiri untuk layanan koleksi perpustakaan bagi para pemakai informasi.

Kemas ulang informasi koleksi perpustakaan disajikan agar informasi yang ada dapat dengan mudah dimanfaatkan dan sesuai dengan kebutuhan pemustaka tanpa harus terlebih dahulu mengumpulkan, memilih dan mengolahnya. Untuk itu layanan kemas ulang informasi sangat diperlukan di perpustakaan sebagai sarana untuk memenuhi kebutuhan informasi dari pemustaka.

\section{Kepustakaan}

Bandono, Bandono dan Susilowati, S. (2021). Pengaruh Pelayanan Perpustakaan Terhadap Prestasi Akademik Mahasiswa Fakultas Seni Rupa ISI Yogyakarta. Abdi Pustaka, 1(1), $15-24$.

Fatmawati, E. (2009). Kemas Ulang Informasi: Suatu Tantangan Bagi Pustakawan. Majalah Media Pustakawan, 16(1\&2), 23-27. https:// ejournal.perpusnas.go.id/mp/issue/view/132

Pebrianti, Y. (2015). Kemas Ulang Informasi: Kumpulan Karya Tulis Ilmiah Peneliti di Lingkup Balai Penelitian dan Pengembangan Budidaya Air Tawar (BPPBAT) Bogor. Jurnal Pari, 1(1), 27-33. http://ejournal-balitbang. kkp.go.id/index.php/JP/article/view/131

Wahyuntini, S., \& Endarti, S. (2021). Tantangan Digital dan Dinamisasi Koleksi dalam Pemanfaatan Koleksi Perpustakaan bagi Prestasi Belajar Mahasiswa. Abdi Pustaka, 1(1), 1-6.

Sulistyo-Basuki. (2009). Pengantar Ilmu 
Perpustakaan. Gramedia Pustaka Utama.

Yulia, Y. (2014). Pengembangan Koleksi. Universitas Terbuka.

\section{Webtografi}

Indonesia, R. (2007). Undang-Undang Republik Indonesia Nomor 43 Tahun 2007 tentang Perpustakaan. https://www.perpusnas.go.id/ law-detail.php?lang=id\&id=170920114322 Ir9g6HhRuc

Jusni, Djatin dan Hartinah, S. (n.d.). Pengemasan dan Pemasaran Informasi: Pengalaman PDIILIPI. Retrieved December 17, 2020, from https://igit.files.wordpress.com/2007/05/ pengemasan-dan-pemasaran-informasipengalaman-pdii-lipi.pdf

Pudjiastuti, S. (n.d.). Mengenal Kemas Ulang Informasi. Retrieved December 2, 2020, from http://p4tkmatematika.org/file/INFO UNIT/ Unit Perpustakaan/kemas Ulang Informasi 2013_4-1.pdf

Reitz, J. M. (2014). Online Dictionary for Library and Information Science. https://products.abcclio.com/ODLIS/odlis_about.aspx

Widyawan, R. (2013). Analis, Sintesis, dan Kemas Ulang. https://rosawidyawan.wordpress.com/ 2013/04/11/analis-sintesis-dan-kemas-ulang/ 